\title{
Coping strategies and perceived stress in Russian army conscripts
}

\author{
Natalya Ulyanova $^{1, *}$, Lida Pravdina $^{2}$ and Sergey Maximets ${ }^{1}$ \\ ${ }^{1}$ Don State Technical University, 344003, Rostov-on-Don, Russia \\ ${ }^{2}$ Southern Federal University, 344006, Rostov-on-Don, Russia
}

\begin{abstract}
The article is devoted to the search for effective patterns of coping with stress in conscripts in different branches of Russian armed forces. The article presents the results of an empirical study of the relationship between coping strategies and the perceived traumatic stress of conscripts $(\mathrm{N}=118)$ serving in the Aerospace, Railway and Air Defense units of the ground forces. Significant differences in indicators of perceived stress and coping among conscripts serving in different types of troops, associated with differences in the conditions of their professional activity, are shown. Multivariate regression analysis revealed the existence of specific coping patterns that involve the rejection of ineffective strategies and the use of effective ones. It is shown that these patterns are not universal, i.e. the effectiveness of the chosen coping strategies differs among ordinary soldiers serving in different branches of the armed forces. Conclusions are drawn about the need to take into account the peculiarities of military service in specific types of units when training and psychological support of conscripts in ways of effective adaptation to the conditions of military service.
\end{abstract}

\section{Introduction}

Research on the mechanisms of coping with stress is extremely relevant in the field of studying the psychological characteristics of military service as a special type of professional activity. A combination of a number of conditions: a rigid social hierarchy, instability of professional tasks, potential or real risk to life and health, difficulties in arranging everyday life, etc. - make military service extremely stressful for the majority of people involved in it [1-3]. This is especially acute in the situation of compulsory military service, when these factors are compounded by the lack of voluntary choice of military service as a professional field [4]. On the one hand, the stress experienced by military personnel, including conscripts, requires careful analysis to develop practical recommendations for improving the effectiveness of their professional activities, and on the other hand, it is of particular research interest, since it allows to detect signs of adaptation and maladaptation that differ in extreme polarity $[5,6]$.

The accumulating stress associated with sharp lifestyle changes and difficult daily conditions of service can lead to the development of traumatic stress, and then - to destructive

\footnotetext{
* Corresponding author: n.y.ulyanova@gmail.com
} 
changes in the psyche. This can be countered by developing coping skills, which is one of the most important elements of an individual's adaptive potential [7]. However, studies of the features of coping strategies of soldiers and officers are more often focused not so much on the prevention of traumatic stress, but on the rehabilitation of military personnel who have already experienced it [1,8-10]. At the same time, the number of studies that study the interaction of traumatic stress and coping in conscripts is small. These two factors determined the idea and direction of our work.

We understand the traumatic stress as a complex of weakly conscious reactions to complex, traumatic circumstances that occur in an individual when enduring an extreme for his life experience [11], or arising as a result of psychological trauma, intense negatively colored experiences in the absence of an individual's ability to adequately cope it [12]. It can be expressed in psychopathological symptoms: anxiety, disturbance, low mood, etc. - and / or in psychosomatic manifestations: sleep and eating disorders, asthenia, headaches, disorders of the cardiovascular system, etc. [13]. Researchers point out that traumatic stress can cause a number of destructive reactions, the strength and severity of which depends on the state of adaptive resources of the individual $[10,14,15$, etc. $]$. Descriptions of the nature and behavioral manifestations of traumatic stress and PTSD in research papers are almost identical, so that in the last decade the concepts of "psychotrauma", "traumatic stress" and "PTSD" are actually used as synonyms $[5,14,16]$. It is important to note that in practice, a complete set of PTSD symptoms is quite rare - its individual manifestations are much more common $[17,18]$, so it is advisable to study its differentiated indicators rather than integral ones.

One of the key elements of the adaptive potential of the individual, which allows coping with TS and preventing its manifestations from turning into chronic pathologies, is coping behavior. It defines as conscious behavior by which an individual can cope with stress or a difficult life situation, while conforming to their own personal characteristics and external conditions [19]. The coping differs from the mechanism of psychological protection by its greater arbitrariness and the desire of the subject to come to an equilibrium state of their own interaction with the environment $[20,21]$.

Due to the peculiarities of the organization of professional activities of conscripts it is necessary to identify clear and measurable indicators of the psychological state of conscripts to study the TS and the ability of individuals to use strategies for coping with it. Based on the provisions of the cognitive theory of stress and the resource approach to the problem of occupational health, we identified two key parameters: the level of perceived TS as an indicator of psychological stress of the individual and the degree of development of coping behavior strategies as an indicator of the possibilities of conscious adaptation to this stress [22]. These indicators are quite diagnostic "markers" of the state of the system of personal resources and are closely interrelated, mutually determining each other: the depletion or inefficient use of adaptive resources leads to an increase in TS, and a decrease in the level of TS increases the probability of successful adaptation [4].

The use of a perceived stress and coping strategies measurement combination is increasingly common in studies of law enforcement officers [3, 23, 24, et al]. It was shown that the use of productive coping strategies is associated with a lower severity of PTSD signs [25], enhancing performance and cognitive function [26] and the development of life skills [27], a decrease in psychological distress [28] and social anxiety [29]. However, this influence is largely determined by factors of the so-called "adaptogenic" context [30], i.e. the specific conditions of a soldier's life. In our opinion, the most powerful factors of the external context for conscripts are the features of their professional tasks: the degree of tension, responsibility, specifics and complexity of their implementation, as well as the characteristics of subculture and social interaction in the units. Both of these factors largely depend on the type of branches in which conscription is performed. However, in the modern literature, there 
are practically no works that would investigate the relationship between coping and traumatic stress of conscripts, taking into account the place of their military service.

The purpose of this study is to study the coping strategies choice features of coscripts in various branches of the armed forces in connection with their subjective assessment of the military service traumatic (stressful) impact.

Hypotheses:

$H_{l}$. The choice of coping strategies and the degree of subjectively perceived stressful influence of military service among coscripts in different branches of the armed forces have significant differences.

$H_{2}$. There are specific patterns of conscripts' choice of coping strategies that make a significant cumulative contribution to perceived stress indicators.

\section{Methods}

Research participants. The study sample consisted of 118 men aged 18 to 22 years $(\mathrm{M}=$ $19.8, \mathrm{Med}=19$ ) who are undergoing compulsory military service in various branches of the armed forces, including:

- $\quad$ aerospace forces $(\mathrm{N}=38)$,

- $\quad$ railway forces $(\mathrm{N}=50)$,

- $\quad$ air defense forces of the ground forces $(\mathrm{N}=30)$.

Methodological tools and studied variables. The study of respondents' subjective assessment of the military service stressful impact on their life was conducted using the questionnaire "Impact of Event Scale - Revised (IES-R)" [31]. The technique includes three subscales: "intrusion", "avoidance", and "hyperarousal", understood as stress response interrelated components to a traumatic experience. To conduct the study, we modified the instructions for respondents: instead of evaluating their attitude to a specific event, they were asked to evaluate their attitude to their own military service experience.

Features of the choice of coping behavior strategies used by military personnel in the course of solving their professional tasks were studied using the questionnaires "Coping Inventory for Stressful Situations" (CISS) [32] and "Strategic Approach to Coping Scale" (SACS) [33]. CISS includes five subscales describing generalized coping models: "taskoriented coping", "emotion-oriented coping", "avoidance-oriented coping", "distraction coping", and "social diversion coping". SACS includes nine subscales describing coping behaviors: "assertive action", "social joining", "seeking social support", "cautious action", "instinctive actions", "avoidance action", "indirect action", "antisocial action", "aggressive action", as well as the integral scale called "constructivity index".

Statistical data processing was performed using the SPSS 21.0 using descriptive analysis methods, comparison of independent samples using the Kruskal-Wallis H-test and the MannWhitney U-test, and multivariate regression analysis. The samples comparison was used to assess the severity of differences in indicators of the military service stress impact and preferred coping strategies among respondents serving in different branches of the military forces. Regression analysis was used to assess the various coping strategies cumulative contribution to the traumatic stress subjective assessment indicators by different groups of respondents. 


\section{Results}

\subsection{Descriptive statistics}

Average and median values and standard deviations were calculated for all the studied variables (table 1).

Table 1. The average (M) and median (Me) values, standard deviations (SD) of indicators for assessing the military service stressful impact and the coping strategies choice for conscripts.

\begin{tabular}{|c|c|c|c|}
\hline & M & Me & SD \\
\hline Perceived stress indicators: & & & \\
\hline Intrusion & 5.12 & 3 & 5.44 \\
\hline Avoidance & 6.26 & 4 & 6.45 \\
\hline Hyperarousal & 4.84 & 1.5 & 6.3 \\
\hline General coping strategies: & & & \\
\hline Emotion-oriented & 50.59 & 50.5 & 10.34 \\
\hline Task-oriented & 31.46 & 30 & 11.26 \\
\hline Avoidance & 42.08 & 44 & 12.82 \\
\hline Distraction & 19.98 & 19.5 & 6.45 \\
\hline Social diversion & 15.3 & 15 & 4.65 \\
\hline Behavioral coping strategies: & & & \\
\hline Assertive action & 20.05 & 20 & 3.86 \\
\hline Social joining & 20.97 & 20 & 4.06 \\
\hline Seeking social support & 20.61 & 20 & 4.08 \\
\hline Cautious action & 21.06 & 21 & 4.11 \\
\hline Instinctive action & 18.13 & 18 & 3.23 \\
\hline Avoidance action & 16.69 & 17 & 3.57 \\
\hline Indirect action & 17.47 & 17 & 3.83 \\
\hline Antisocial action & 16.05 & 16 & 4.74 \\
\hline Aggressive action & 14.69 & 14 & 4.52 \\
\hline Constructivity index & 1.36 & 1.26 & 0.4 \\
\hline
\end{tabular}

\subsection{The coping strategies and perceived stress assessment by respondents serving in different branches of the military forces}

To test the first hypothesis, we used an independent samples comparison using the KruskalWallis-Test (table 2). A subjective assessments comparison of the military service traumatic (stressful) impact on conscripts and their preferred coping strategies showed significant ( $\mathrm{p} \leq$ 0.001) differences between groups of respondents in the following indicators: a) all parameters for perceived stress assessing (intrusion, avoidance, hyperarousal), b) general coping strategies: task-oriented, avoidance, distraction, social diversion, c) behavioral coping strategies: assertive action, social joining, seeking social support, cautious action, indirect action, antisocial action, aggressive action, as well as the "constructivity index" integral parameter.

Table 2. Significant differences in indicators for assessing the military service stressful impact and the coping strategies choice for individuals performing military service in different conditions

(Kruskal-Wallis-Test).

\begin{tabular}{|c|c|c|c|}
\hline & $\chi^{\mathbf{2}}$ & df & p \\
\hline Perceived stress indicators: & & & \\
\hline Intrusion & 36.7 & 2 & .000 \\
\hline Avoidance & 24.14 & 2 & .000 \\
\hline
\end{tabular}




\begin{tabular}{|c|c|c|c|}
\hline Hyperarousal & 34.34 & 2 & .000 \\
\hline General coping strategies: & & & \\
\hline Emotion-oriented & 21.03 & 2 & .000 \\
\hline Task-oriented & 52.66 & 2 & .000 \\
\hline Avoidance & 67.33 & 2 & .000 \\
\hline Distraction & 47.51 & 2 & .000 \\
\hline Social diversion & 40.15 & 2 & .000 \\
\hline $\begin{array}{c}\text { Behavioral coping } \\
\text { strategies: }\end{array}$ & & & \\
\hline Assertive action & 23.63 & 2 & .000 \\
\hline Social joining & 29.2 & 2 & .000 \\
\hline Seeking social support & 20.88 & 2 & .000 \\
\hline Cautious action & 18.42 & 2 & .000 \\
\hline Indirect action & 18.97 & 2 & .000 \\
\hline Antisocial action & 49.07 & 2 & .000 \\
\hline Aggressive action & 44.03 & 2 & .000 \\
\hline Constructivity index & 57.56 & 2 & .000 \\
\hline
\end{tabular}

The refinement of the data obtained by pairwise comparison of groups of respondents using the Mann-Whitney U-test revealed the following patterns:

1. Differences in all indicators of the military service stress impact are significant for all three groups of respondents: conscripts serving in the aerospace forces units assess the stress level higher than those serving in other branches of the armed forces $\left(U_{\text {emp }}\right.$ takes values from $137,0$ to $579,5, \mathrm{p} \leq 0,01)$, and the conscripts serving in the railway forces determine their own stress level higher than those serving in the air defense forces of the ground forces unit ( $\mathrm{U}_{\text {emp }}$ takes values from 357,5 to $530,0, \mathrm{p} \leq 0,01$ ).

2. Typically the constructivity index indicators are significantly greater for the conscripts serving in the air defense forces of the ground forces than for those of the aerospace and railway forces $\left(U_{\text {emp }}=197,5, p \leq 0,01\right.$ and $U_{\text {emp }}=264,5, p \leq 0,01$, respectively), and for the railway forces conscripts the constructivity index indicators are significantly greater than for those of the aerospace forces $\left(\mathrm{U}_{\mathrm{emp}}=432,5, \mathrm{p} \leq 0,01\right)$.

3. The railway forces conscripts use strategies related to avoiding a stressful situation: "avoidance", "distraction", "social diversion", "seeking social support", "indirect action" ( $\mathrm{U}_{\mathrm{emp}}$ takes values from 128,5 to $456,0, \mathrm{p} \leq 0,01$ ), as well as the "task-oriented coping" strategy $\left(\mathrm{U}_{\mathrm{emp}}=431,5, \mathrm{p} \leq 0,01\right.$ and $\left.\mathrm{U}_{\mathrm{emp}}=456,0, \mathrm{p} \leq 0.01\right)$. They do it significantly more often than other conscripts' groups who participated in the study.

4. The conscripts of the air defense and railway forces units use the "assertive action" constructive strategy more often than the aerospace forces conscripts $\left(U_{\text {emp }}=220,0, p \leq 0,01\right.$ and $U_{\text {emp }}=475,0, p \leq 0,01$, respectively).

5. The differences in the use of unconstructive coping strategies: "aggressive action", "antisocial action", "emotion-oriented coping" — are two-stage in nature: the aerospace forces conscripts used them significantly more often than the conscripts of the two other military forces in question ( $U_{\text {emp }}$ takes the values of 158,5 to of $345,0, p \leq 0,01$ ), and the railway forces conscripts do it more often than those of the air defense forces $\left(\mathrm{U}_{\mathrm{emp}}\right.$ ranges from 128,0 to $346,0, \mathrm{p} \leq 0,01)$.

\subsection{Coping contribution to the perceived stress level}

The second research hypothesis testing using multivariate regression analysis showed that the preferred by the conscripts coping strategies form certain complexes that make a cumulative contribution to the perceived stress level. These complexes were slightly different 
from each other (table 3, a-c) for different groups of respondents (the aerospace, railway, and air defense forces conscripts).

Table 3. Multivariate regression analysis results of the aggregate contribution of respondents' preferred coping strategies to their assessment of the military service traumatic impact.

\begin{tabular}{|c|c|c|c|c|}
\hline \multicolumn{5}{|c|}{ a) the aerospace forces conscripts: } \\
\hline \multirow{2}{*}{$\begin{array}{c}\text { Perceived } \\
\text { stress } \\
\text { indicators } \\
\text { (dependent } \\
\text { variable) }\end{array}$} & \multirow[b]{2}{*}{ Coping strategies (independent variables) } & \multicolumn{3}{|c|}{ Model parameters } \\
\hline & & Adjusted $\mathbf{R}^{2}$ & $\beta$ & $\mathbf{p}$ \\
\hline Hyperarousal & $\begin{array}{l}\text { Emotion-oriented coping } \\
\text { Avoidance-oriented coping }\end{array}$ & 0.25 & $\begin{array}{c}0.52 \\
-0.44\end{array}$ & $\begin{array}{l}0.002 \\
0.007\end{array}$ \\
\hline \multicolumn{5}{|c|}{ b) the railway forces conscripts: } \\
\hline \multirow{2}{*}{$\begin{array}{l}\text { Perceived } \\
\text { stress } \\
\text { indicators } \\
\text { (dependent } \\
\text { variable) } \\
\end{array}$} & \multirow[b]{2}{*}{ Coping strategies (independent variables) } & \multicolumn{3}{|c|}{ Model parameters } \\
\hline & & Adjusted $\mathbf{R}^{2}$ & $\boldsymbol{\beta}$ & $\mathbf{p}$ \\
\hline Intrusion & $\begin{array}{l}\text { Emotion-oriented coping } \\
\text { Assertive action }\end{array}$ & 0.29 & $\begin{array}{c}0.40 \\
-0.28\end{array}$ & $\begin{array}{l}0.003 \\
0.033\end{array}$ \\
\hline \multirow[b]{2}{*}{ Avoidance } & Emotion-oriented coping & 0.15 & 0.41 & 0.003 \\
\hline & \begin{tabular}{|l|} 
Assertive action \\
Distraction coping
\end{tabular} & 0.14 & $\begin{array}{l}-0.34 \\
-0.28 \\
\end{array}$ & $\begin{array}{l}0.014 \\
0.042\end{array}$ \\
\hline \multicolumn{5}{|c|}{ c) the air defense forces conscripts: } \\
\hline \multirow{2}{*}{$\begin{array}{l}\text { Perceived } \\
\text { stress } \\
\text { indicators } \\
\text { (dependent } \\
\text { variable) }\end{array}$} & \multirow[b]{2}{*}{ Coping strategies (independent variables) } & \multicolumn{3}{|c|}{ Model parameters } \\
\hline & & Adjusted $\mathbf{R}^{2}$ & $\boldsymbol{\beta}$ & $\mathbf{p}$ \\
\hline Avoidance & $\begin{array}{l}\text { Task-oriented coping } \\
\text { Antisocial action }\end{array}$ & 0.21 & $\begin{array}{l}0.41 \\
0.35 \\
\end{array}$ & $\begin{array}{l}0.019 \\
0.043\end{array}$ \\
\hline \multirow{2}{*}{ Hyperarousal } & Social joining & 0.13 & 0.40 & 0.030 \\
\hline & Seeking social support & 0.11 & 0.37 & 0.043 \\
\hline
\end{tabular}

Note: regression models with the highest values of the determination coefficient (adjusted $\mathrm{R}^{2} \geq 0,10$ ) are shown.

The most significant predictor of the formation of a stressful reaction to the military service conditions is the use of the emotion-oriented coping for respondents who are the aerospace and railway forces conscripts. At the same time, the values of the regression coefficients $\beta$ for the variable "emotion-oriented coping" in regression models are positive, i.e. the choice of this type of coping is associated with increased traumatic stress. The regression models predictive accuracy increases if we take into account the negative contribution of respondents' choice of avoidance-oriented coping (for the aerospace forces conscripts) and coping associated with assertive action (for the railway forces conscripts) along with emotion-oriented coping. In other words, the use of "avoidance" and "assertive action" strategies by the aerospace and railway forces conscripts respectively, while simultaneously rejecting emotion-oriented coping, allows to reduce statistically significantly the indicators of the military service stressful impact. A similar result was obtained for the "assertive actions" and "social diversion" coping strategies: the simultaneous use of these strategies significantly reduces the "avoidance" traumatic stress indicator severity in the railway forces conscripts.

The respondents who serve in the air defense forces of the ground forces are characterized by slightly different patterns of the coping strategies contribution to the perceived stress 
indicators. Thus, the "avoidance" stress response indicator is positively associated with the simultaneous choice of task-oriented coping and antisocial actions, the "hyperarousal" indicator is associated with the "social joining" and "seeking social support" strategies.

At the same time, some coping strategies ("distraction coping", "cautious action", "indirect actions", etc.) were not included in any of the complexes that contribute to the indicators of the military service stressful impact on the conscripts.

\section{Discussion}

The differences in respondents' assessment of the military service stressful impact on their life indicate that among those studied in this work the aerospace conscription conditions are subjectively the most difficult, somewhat less difficult — in the railway forces, and the lightest - in the air defense forces of the ground forces. It can be assumed that the key differences between the three studied Armed Forces structures that affect the conscripts' stress level are their professional activities specifics and the features of socio-psychological relations within the military units. Thus, young men who have passed a more rigorous selection both for health reasons and for the level of existing competencies are called to the ranks of the aerospace forces where performing professional duties is associated with a fairly high level of responsibility for the aviation equipment and auxiliary equipment serviceability. This leads, on the one hand, to increased competitive relations among soldiers, and on the other hand — to high requirements for compliance with military discipline and hierarchy. The railway forces military service involves fewer requirements for conscripts at the selection stage, but involves performing quite complex, often involving significant physical effort types of work to restore and ensure the functioning of key railway lines. The conscription in the ground forces, which include the air defense forces, is associated with less competitive selection and relative stability of performed tasks, which may help reduce its stress from the point of view of recruits. At the same time, the limited sample size does not allow us to make a clear conclusion about whether the specific professional tasks associated with military service in certain branches of the armed forces or the service conditions in a particular military unit, on the basis of which the empirical research data was collected, is the determining factor of the respondents' stress response.

The coping strategies choice by respondents from different groups is generally consistent with differences in the subjective assessment of their traumatic stress received during military service. The least constructive ways of coping are typical for the aerospace forces conscripts: this is probably due to their general maladaptation to complex professional tasks and the social environment high competitiveness. In contrast, the air defense forces conscripts are more likely to demonstrate constructive coping strategies and a high level of constructivity, which may be due to the lower level of requirements imposed on them and more lenient conditions of military service. In this regard, it is interesting that the soldiers of the railway forces units more often than other respondents choose the "task-oriented coping" strategy, which is traditionally understood by psychologists as the best way to cope, but the level of traumatic stress is estimated by them as average. Probably, this fact is explained by the peculiarity of the military units' organizational structure, in which an attempt to independently eliminate emerging problems (both in professional activities and in social interaction) is most often perceived by higher-ranking military personnel as a violation of the hierarchy, and task-oriented coping is ineffective for the conscripts. Thus, human activity specific conditions become the most important success predictor of various coping strategies, and the individual's adaptive potential is determined not so much by the possession of specific "constructive" coping methods, but by the willingness to change the coping repertoire depending on the social and professional environment requirements. 
The cumulative contribution study of the coping strategies choice to the conscripts' traumatic stress indicators showed that regression models that simultaneously take into account the influence of two or more types of coping behavior often have a higher percentage of the explained variance (adjusted $\mathrm{R}^{2}$ ) than single-factor regression models. Thus, taking into account several types of coping strategies used by respondents at the same time makes it possible to more accurately predict the risk of a stressful reaction to the military service conditions.

The main factor in increasing traumatic stress in the aerospace and railway forces conscripts was the choice of a coping strategy associated with emotional response to difficulties. On the one hand, this is consistent with the generally accepted understanding of such a strategy as non-constructive, on the other hand, it is supported by an extremely masculinized professional subculture, which is characterized by an unspoken ban on the strong emotions manifestation. At the same time, the relationship between emotion-oriented coping and traumatic stress can be enhanced when other coping strategies are abandoned. It is important to note that the factors that strengthen or weaken this effect differ among soldiers serving in different branches of the armed forces. In particular, for the aerospace forces conscripts the constructive pattern of coping with stress is the emotional coping rejection and training in coping associated with avoiding a conflict situation. The constructive pattern is somewhat different for the railway forces conscripts: reducing the stress response for them can be achieved by giving up emotional coping in combination with training in assertive actions and ways of distraction through entering into social communication.

A completely different picture of the relationship between coping strategies and traumatic stress is typical for the conscripts in the air defense forces of the ground forces. Coping strategies that are traditionally considered "constructive" ("task-oriented coping", "social joining", and "seeking social support") make a positive contribution to the respondents' stress response indicators, i.e. their use contributes to increased traumatization along with the destructive "antisocial action" strategy. This is probably due to the high level of social isolation of soldiers at air defense facilities, as well as the general attitude to the inadmissibility of showing "weakness" or empathy towards colleagues, peculiar to the army subculture. Thus, for the respondents of this group, an effective way of socio-psychological adaptation to the military service conditions will be not so much training in constructive coping, but rather creating conditions for meeting social needs - for example, strengthening individual psychological support for conscripts.

Thus, a number of general patterns can be identified: for example, the use of emotionoriented coping by the conscripts, as well as task-oriented coping and seeking social support, are associated with an increase in traumatic stress, and the rejection of it while using avoidant strategies or assertive actions is associated with its weakening. Task-oriented coping and seeking social support, contrary to their traditional understanding as constructive and even optimal ways of coping, contribute to the strengthening of the military service traumatic impact on conscripts.

The obtained data allow us to judge the both research hypotheses confirmation. The study results indicate the complex nature of the relationship between coping strategies and the traumatic stress level and the need to additionally take into account the military service peculiarities when training conscripts to respond constructively to stressors. This clarifies and complements the existing theoretical ideas about the coping role in the conscripts' training and adaptation to the military service.

At the same time, the study limitations include incomplete representation in the sample of the armed forces' various branches, as well as the conscripts in the same branches, but in different military units. To clarify the data obtained, we plan to conduct an additional study with the sample expansion, as well as to include representatives of other extreme professions (rescuers, firefighters, etc.). In addition, due to the limited scope of the studied variables, the 
question of mediating the relationship between coping and traumatic stress by other factors, including personal, cognitive and other characteristics of soldiers, group characteristics of specific units, etc. is still unsolved. The study of these factors provides a perspective for expanding and deepening the presented research.

\section{Conclusions}

The study results of subjective assessment of the military service traumatic stress impact and coping strategies of the conscripts in different armed forces branches allowed us to formulate a number of conclusions:

1. The conscripts in various armed forces branches (the aerospace forces, the railway forces, the air defense forces of the ground forces) differ significantly in their subjective assessment of the military service traumatic impact on them and their preference for various strategies for coping with stress. The traumatic stress highest indicators and the most frequent choice of non-constructive strategies characterize individuals serving in the ranks of the aerospace forces, the lowest are in the air defense forces of the ground forces, which indirectly shows the role of professional tasks and the conscription conditions in the level of its stress for conscripts and the success of their adaptation to military service.

2. There are patterns of using multiple coping strategies at the same time that contribute to an increase or decrease in the traumatic stress level subjective assessment, specific to soldiers serving in different branches of the armed forces. A stable relationship between the coping strategy choice and the trauma level during military service is observed for the "emotion-oriented coping" strategy, which contributes to an increased stress response for respondents serving in the aerospace and railway forces. For the air defense forces of the ground forces conscripts increased stress is associated with the seeking social support and task-oriented coping. Coping strategies associated with assertive actions and avoidance or social diversion generally contribute to reducing the stress response, while avoiding emotionoriented coping, this effect is enhanced.

3. Psychological training and support of military personnel on a conscription basis should include training in constructive ways of coping with traumatic stress, taking into account the specifics of the conditions in which their professional activities are performed, and the features of the relationship between coping strategies and traumatic stress characteristic of these conditions. In particular, when accompanying the conscripts who serve in conditions of high competition and tension, typical for the aerospace forces and, to a lesser extent, for the railway forces, it is necessary to pay attention to the development of assertiveness skills and the ability to take a "constructive pause" while simultaneously rejecting non-constructive displays of emotions. To improve the adaptation effectiveness of the conscripts serving in conditions of noticeable social isolation, it is necessary to ensure the possibility of obtaining support by strengthening psychological assistance or changing the intragroup attitudes of soldiers themselves from competitive to mutually supportive.

\section{References}

1. R.F. Armenta, T. Rush, C.A. Leard Mann, et al., BMC Psychiatry 18, 48 (2018) DOI: 10.1186/s12888-018-1590-5

2. D. Davison, BMJ Mil Health (2020) DOI: 10.1136/bmjmilitary-2020-001432.

3. A.R. Gomes, J.M. Afonso, Avances en Psicología Latinoamericana 34(1), 47-65 (2016) DOI: 10.12804/apl34.1.2016.04

4. J.H. Ha, J. Jue, Y. Jang, Military Medicine 114 (2020) DOI: 10.1093/milmed/usaa114 
5. Y. Danyk, O. Druz, I. Chernenko, Journal of Education, Health and Sport 7(6), 12651279 (2017) DOI: 10.5281/zenodo.2550586

6. J.F. Villaruz Fisak, B.S. Turner, K. Shepard, S.P. Convoy, Military Medicine usaa171 (2020) DOI: 10.1093/milmed/usaa171

7. D.M. Desmond, M. MacLachlan, Social science \& medicine 62(1), 208-216 (2006) DOI: 10.1016/j.socscimed.2005.05.011

8. N. Ghaffarzadegan, A. Ebrahimvandi, M.S. Jalali, PLoS ONE 11(10), e0161405 (2016) DOI: 10.1371/journal.pone.0161405

9. E. Mattson, L. James, B. Engdahl, Military medicine 183(9-10), 475-480 (2018) DOI: 10.1093/milmed/usx201

10. N.P. Mota, J.M. Cook, N.B. Smith, et al., Journal of psychiatric research 119, 23-31 (2019) DOI: 10.1016/j.jpsychires.2019.09.005

11. M.B. Williams, S. Poijula, The PTSD workbook: Simple, effective techniques for overcoming traumatic stress symptoms (New Harbinger Publications, Oakland, 2016) ISBN:1626253706

12. L.D. Butler, J. Carello, E. Maguin, Psychological Trauma: Theory, Research, Practice, and Policy 9(4), 416-424 (2017) DOI: 10.1037/tra0000187

13. E.I. Fried, M.B. Eidhof, S. Palic, et al., Clinical Psychological Science 6(3), 335-351 (2018) DOI: $10.1177 / 2167702617745092$

14. Y. Auxemery, La Presse Médicale 47(5), 423-430 (2018) DOI: 10.1016/j.lpm.2017.12.006

15. J.D. Elhai, A.A. Contractor, M. Tamburrino, et al., Journal of Affective Disorders 175, 373-378 (2015) DOI: 10.1016/j.jad.2015.01.034

16. E.B. Foa, T.M. Keane, M.J. Friedman, J.A. Cohen, Effective treatments for PTSD (Guilford Publications, N.Y., 2020) ISBN: 1572305843

17. R.C. Kessler, S. Aguilar-Gaxiola, J. Alonso, et al., European journal of psychotraumatology 8(5), 1353383 (2017) DOI: 10.1080/20008198.2017.1353383

18. B.T. Litz, A.A. Contractor, C. Rhodes, et al., Journal of traumatic stress 31(2), 286-295 (2018) DOI: $10.1002 /$ jts. 22276

19. R. Delahaij, K. Van Dam, Personality and Individual Differences 119, 13-18 (2017) DOI: $10.1016 /$ j.paid.2017.06.021

20. O.S. Deyneka, E.R. Isaeva, Psychology in Russia 10(1), 130-145 (2017) DOI: 10.11621/pir.2017.0110

21. U. Kramer, Psychology and psychotherapy: theory, research and practice 83(2), 207221 (2010) DOI: 10.1111/1467-6494.00037

22. L.R. Pravdina, N.Yu. Ulyanova, Psychology and psychotechnics 2(101), 59-73 (2017) DOI: $10.7256 / 2454-0722.2017 .2 .23301$

23. L.G.M. Kruijff et al., Military Medical Research 6(1), 9-16 (2019) DOI: 10.1186/s40779-019-0199-4

24. D.L. Padden, R.A. Connors, J.G. Agazio, Western Journal of Nursing Research 33(2), 247-267 (2011) DOI: 10.1177/0193945910371319

25. T.W. Britt, A.B. Adler, G. Sawhney, P.D. Bliese, Journal of Traumatic Stress 30(5), 491501 (2017) DOI: 10.1002/jts.22221

26. A.E. Jensen, J.R. Bernards, et al., Frontiers in Psychology 10, 2964 (2020) DOI: 10.3389/fpsyg.2019.02964 
27. S.J. Hosseini-Shokouh, P. Dabaghi, S. Rahimi, Deschideri Postmoderne 9(2), 254-268 (2018) DOI: $10.18662 / \mathrm{po} / 31$

28. C. Nakkas, H. Annen, S. Brand, Neuropsychiatric disease and treatment 12, 2237-2243 (2016) DOI: $10.2147 /$ ndt.s113220

29. A. Aldao et al., Journal of anxiety disorders 28(4), 382-389 (2014) DOI: 10.1016/j.janxdis.2014.03.005

30. V. Terziev, Proceedings of 6th International Conference on Education and Social Sciences (OCERINT, Istanbul, 2019) ISBN: 978-605-82433-5-4.

31. D.S. Weiss, C.R. Marmar, The impact of event scale-revised. Assessing psychological trauma and PTSD (Guilford, New York, NY, 2004) ISBN-13: 978-1593850357

32. K. Han, G.N. Burns, N.C. Weed, G.T.,Hatchett, N.K. Kurokawa, Educational and Psychological Measurement 69(4), 675-695 (2009)

33. T.N. Banshchikova, M.L. Sokolovskii, V.A. Solomonov, E.A. Fomina, Modern Journal of Language Teaching Methods 9(1), 423-425 (2019) DOI: 10.26655/mjltm.2019.1.1 